\title{
Editorial
}

\section{Advances in Antennas for Wireless Identification and Sensing Systems}

\author{
Leena Ukkonen, ${ }^{1}$ Harish Rajagopalan, ${ }^{2}$ and Fan Yang ${ }^{3}$ \\ ${ }^{1}$ Department of Electronics and Communications Engineering, Tampere University of Technology, 33720 Tampere, Finland \\ ${ }^{2}$ Department of Electrical Engineering, University of California, Los Angeles, Los Angeles (UCLA), CA 90095, USA \\ ${ }^{3}$ Electronic Engineering Department, Tsinghua University, Beijing 100084, China
}

Correspondence should be addressed to Leena Ukkonen; leena.ukkonen@tut.fi

Received 20 January 2013; Accepted 20 January 2013

Copyright (C) 2013 Leena Ukkonen et al. This is an open access article distributed under the Creative Commons Attribution License, which permits unrestricted use, distribution, and reproduction in any medium, provided the original work is properly cited.

Wireless identification and sensing systems are emerging in everyday use and the demand for ubiquitous automatic cognition and wireless sensing is growing rapidly $[1,2]$. For example, passive sensors are critical and highly desirable in remote sensing platforms, where long term environment controlling and monitoring take place. Important features for the design of these sensors are that the sensor is wireless, battery-free, compact, and easy to integrate with other wireless passive sensors [3]. In addition, the growth of biosensors and health-related monitoring devices has accentuated the need for miniaturized, high-efficiency conformal sensing devices that can operate over a wide range of frequencies and are integrable in wearable and lightweight configurations [4]. For example, recently published "electronic tattoo" [5] presents an emerging wave of ideas of integrating sensors and other flexible electronic devices directly on human body. Electronic tattoo is a thin, extremely flexible device which has the same mechanical properties of skin to facilitate seamless attachment to the surface of skin.

Moreover, identification and monitoring of objects are needed in various supply chains and everyday logistics $[6,7]$. Requirements in life cycle management (LCM) of different products have increased rapidly. For example, in construction business the condition and moisture of building structures are an important monitoring area. Also in the field of consumer electronics it is important to be able to monitor and manage the life cycle of products all the way from manufacturing to recycling.

Efficient wireless identification and sensing platforms have a huge potential to enhance the quality of life, for example, in the fields of healthcare, security, and efficient use of available natural resources [8-11]. Antennas are one of the key components in achieving the desired efficient intelligent wireless platforms. In these future platforms, antennas should be small in size, efficient, and manufacturable with additive methods on environmentally friendly low cost substrates, such as paper. They should also be platform tolerant to enable attachment on various platform materials $[2,12,13]$. In addition, carbon nanotubes (CNTs) and graphene are attractive nanoscale materials which have been gaining a great interest in the research world recently $[13,14]$. Their unique mechanical, electrical, and thermal properties make them promising building blocks for a large variety of applications in microelectronics and nanotechnologies [15]. In particular, CNTs are expected to address effectively numerous common electronic system challenges, such as tunability and miniaturization.

Recently, sensing methods based on the changes, for example, in the electrical properties of materials integrated with radio frequency identification (RFID) tag antennas, have gained a lot of interest within research groups globally [2, $8,16]$. Operation principle of passive RFID tag-integrated sensors can be based on the effects of change in the electrical properties of the sensing material on the performance of the RFID tag. No discrete or microchip-integrated sensor component is used in this kind of sensor tags. For example, permittivity of distilled water changes as a function on ambient temperature [16]. A sealed water pocket on top of the tag antenna's matching circuit affects the impedance matching between the tag's antenna and the microchip by 
changing the input impedance of the tag antenna. Change in the impedance matching in turn affects the optimum operating frequency of the sensor tag, which serves as an indicator of temperature change or of a specific temperature value.

This special issue presents articles containing newest developments of antennas in wireless identification and sensing systems. In the paper entitled "Dual-Band Antenna/AMC Combination for RFID” M. E. de Cos and F. Las-Heras present a novel antenna-artificial magnetic conductor (AMC) combination usable in dual-band radio frequency identification (RFID) tags over metallic objects.

To address the miniaturization requirements, X. Ren et al. propose a novel electrically small antenna (ESA) based on the meandered line structure in their paper entitled " $A$ Novel Electrically Small Meandered Line Antenna with a TridentShaped Feeding Strip for Wireless Applications."

Ultrahigh-frequency (UHF) approaches have caught increasing attention recently and have been considered as a promising technology for online monitoring of partial discharge (PD) signals. The paper entitled "Resonant Frequency Calculation and Optimal Design of Peano Fractal Antenna for Partial Discharge Detection" by J. Li et al. presents a Peano fractal antenna for UHF PD online monitoring of transformer with small size and multiband features.

To improve the cost-efficiency of novel ink jet printed RFID tag antennas, J. Virtanen et al. present a paper entitled "A Selective Ink Deposition Method for the Cost-Performance Optimization of Inkjet-Printed UHF RFID Tag Antennas". The deposition method is based on identifying areas with high surface current densities on a given tag antenna and applying additional silver nanoparticle ink onto such areas to increase tag read range.

The paper written by C. Kakoyiannis and P. Constantinou, entitled "Compact, Slotted, Printed Antennas for DualBand Communication in Future Wireless Sensor Networks," describes how printed antennas, especially inverted-F antennas (IFAs) can be efficiently designed as simple, compact, device-integrated, dual-band antennas.

All papers appearing in this special issue have been subject to a strict peer reviewing process. They are of high quality and address the area of antennas for wireless identification and sensing systems from different perspectives. It is our expectation that through this special issue, some valuable ideas and conclusions on this challenging topic are provided. In addition, we hope that the published papers provoke new ideas and research in this area.

Leena Ukkonen Harish Rajagopalan Fan Yang

\section{References}

[1] T. T. Thai, L. Yang, G. R. Dejean, and M. M. Tentzeris, "Nanotechnology enables wireless gas sensing," IEEE Microwave Magazine, vol. 12, no. 4, pp. 84-95, 2011.

[2] R. Vyas, V. Lakafosis, A. Rida et al., "Paper-based RFID-enabled wireless platforms for sensing applications," IEEE Transactions on Microwave Theory and Techniques, vol. 57, no. 5, pp. 1370$1382,2009$.

[3] T. T. Thai, J. M. Mehdi, H. Aubert et al., "A novel passive wireless ultrasensitive RF temperature transducer for remote sensing," in Proceedings of the IEEE International Microwave Symposium (IMS '10), pp. 473-476, May 2010.

[4] A. Traille, L. Yang, A. Rida, and M. M. Tentzeris, "A novel liquid antenna for wearable bio-monitoring applications," in Proceedings of the IEEE International Microwave Symposium Digest (MTT '08), pp. 923-926, June 2008.

[5] J. Cartwright, "Electronic skin grafts gadgets to body," ScienceNOW, August 2011, http://news.sciencemag.org/sciencenow/2011/08/electronic-skin-grafts-gadgets-t.html.

[6] A. Lehto, J. Nummela, L. Ukkonen, L. Sydanheimo, and M. Kivikoski, "Passive UHF RFID in paper industry: challenges, benefits and the application environment," IEEE Transactions on Automation Science and Engineering, vol. 6, no. 1, pp. 66-79, 2009.

[7] J. Nummela, K. Määttänen, L. Ukkonen, and L. Sydänheimo, "Utilizing UHF RFID in supply chains: examples from similarities in paper and cell phone industries," International Journal of Latest Trends in Computing (IJLTC), vol. 2, no. 3, 2011.

[8] C. Occhiuzzi and G. Marrocco, "The RFID Technology for Neurosciences: feasibility of limbs' monitoring in sleep diseases," IEEE Transactions on Information Technology in Biomedicine, vol. 14, no. 1, pp. 37-43, 2010.

[9] H. Rajagopalan and Y. Rahmat-Samii, "Ingestible RFID biocapsule tag design for medical monitoring," in Proceedings of the IEEE International Symposium on Antennas and Propagation, July 2010.

[10] L. Yang, R. Vyas, A. Rida, J. Pan, and M. Tentzeris, "Wearable RFID-enabled sensor nodes for biomedical applications," in Proceedings of the IEEE Electronic Components and Circuits Conference, pp. 2156-2159, 2008.

[11] J. Virtanen, L. Ukkonen, T. Björninen, and L. Sydänheimo, "Printed Humidity Sensor for UHF RFID Systems," in Proceedings of the Sensors Applications Symposium (SAS '10), pp. 269272, IEEE, February 2010.

[12] J. Virtanen, T. Björninen, L. Ukkonen, and L. Sydänheimo, "Passive UHF inkjet-printed narrow-line RFID tags," IEEE Antennas and Wireless Propagation Letters, vol. 9, pp. 440-443, 2010.

[13] M. M. Tentzeris, "Inkjet-printed paper-based RFID and nanotechnology-based ultrasensitive sensors: The "Green" ultimate solution for an ever improving life quality and safety?" in Proceedings of the IEEE Radio and Wireless Symposium (RWS '10), pp. 120-123, January 2010.

[14] B. H. Kim, T. H. Park, S. J. Baek et al., "N -type carbon nanotube by alkaline-earth metal Sr doping," Journal of Applied Physics, vol. 103, no. 9, Article ID 096103, 2008.

[15] R. De Paolis, S. Pacchini, F. Coccetti et al., "Circuit model of carbon-nanotube inks for microelectronic and microwave tunable devices," in Proceedings of the IEEE International Microwave Symposium (IMS '11), June 2011.

[16] J. Virtanen, L. Ukkonen, T. Björninen, A. Z. Elsherbeni, and L. Sydänheimo, "Temperature sensor tag for passive UHF RFID systems," in Proceedings of the IEEE Sensor Applications Symposium, pp. 312-317, San Antonio, Tex, USA, February 2011. 

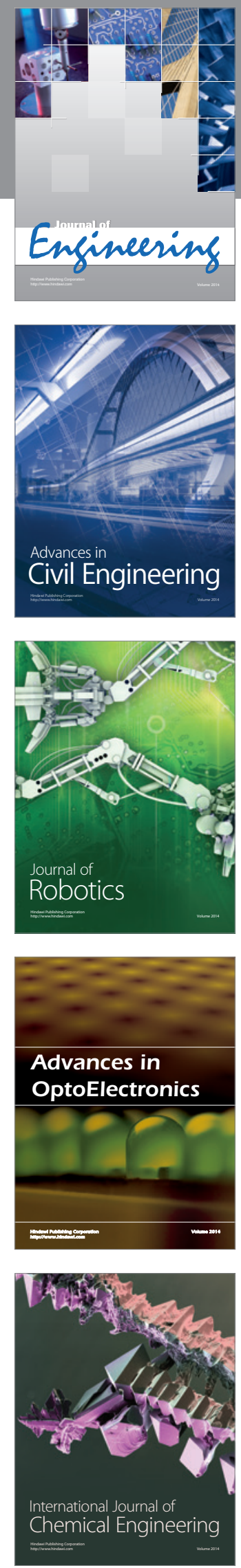

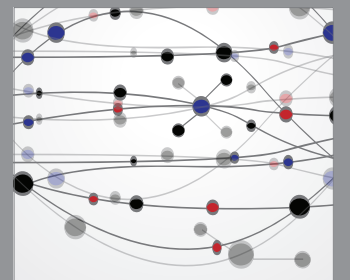

The Scientific World Journal
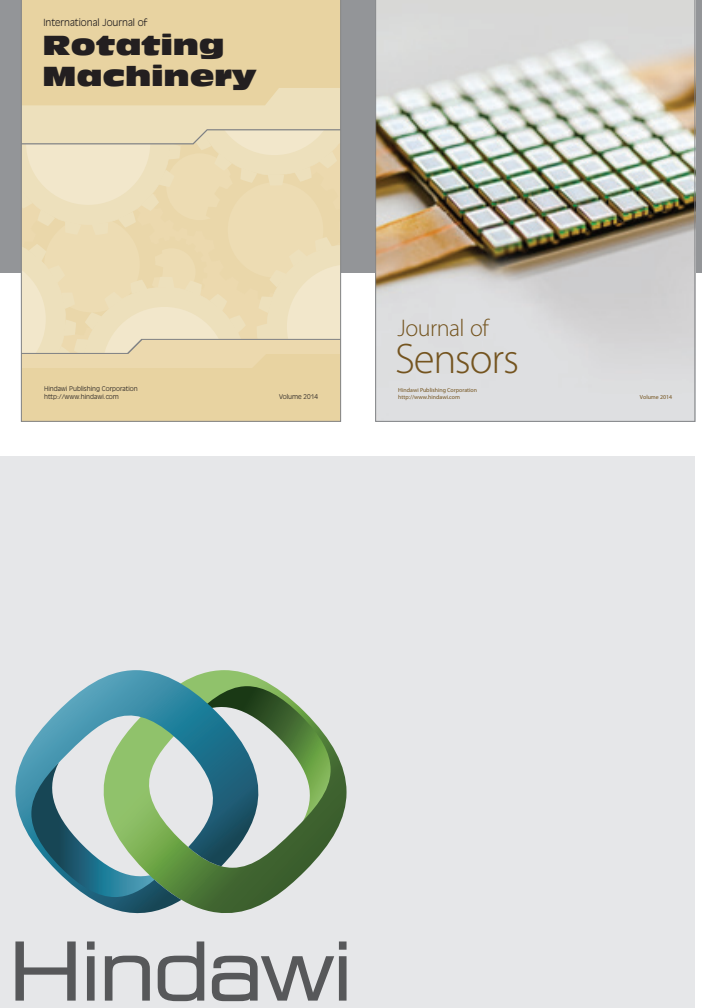

Submit your manuscripts at http://www.hindawi.com
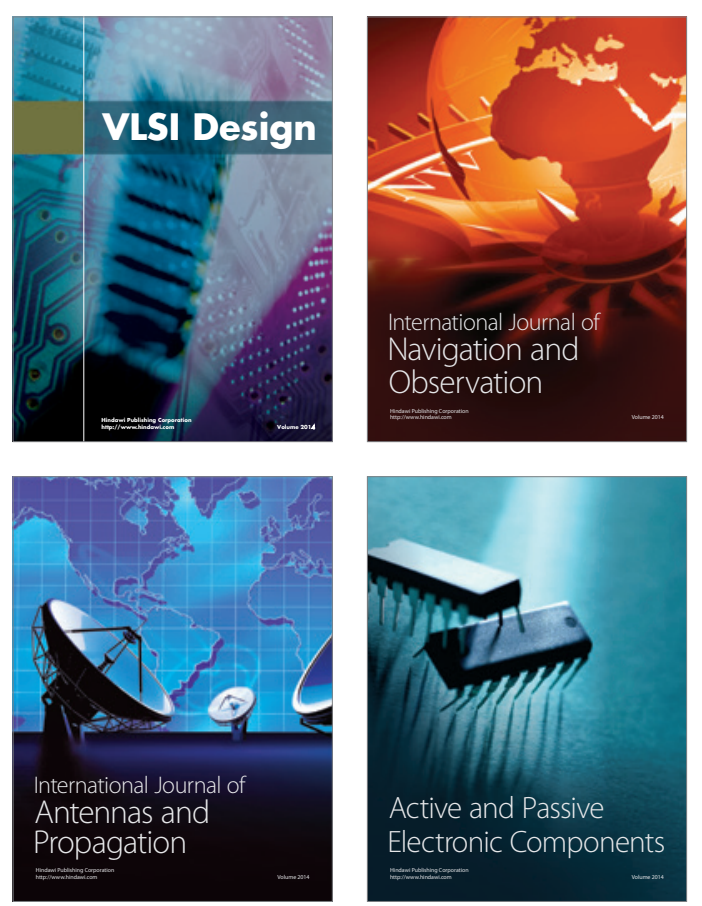
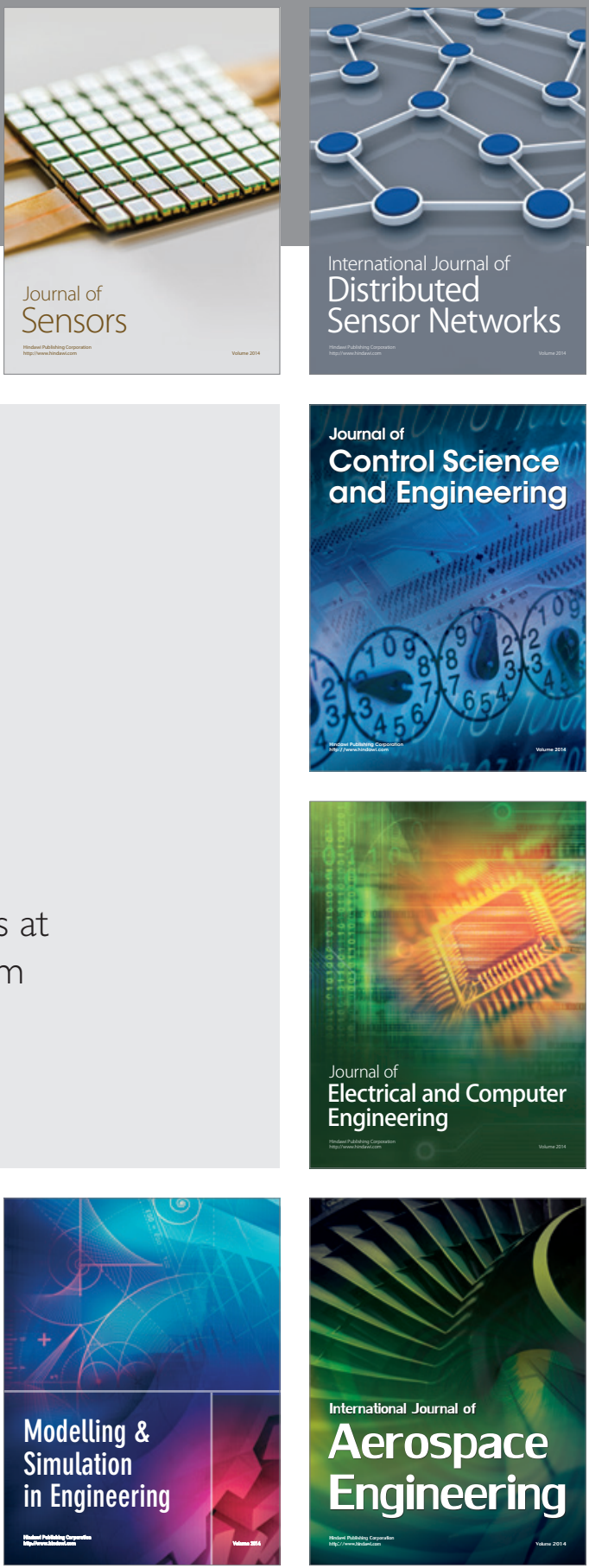

Journal of

Control Science

and Engineering
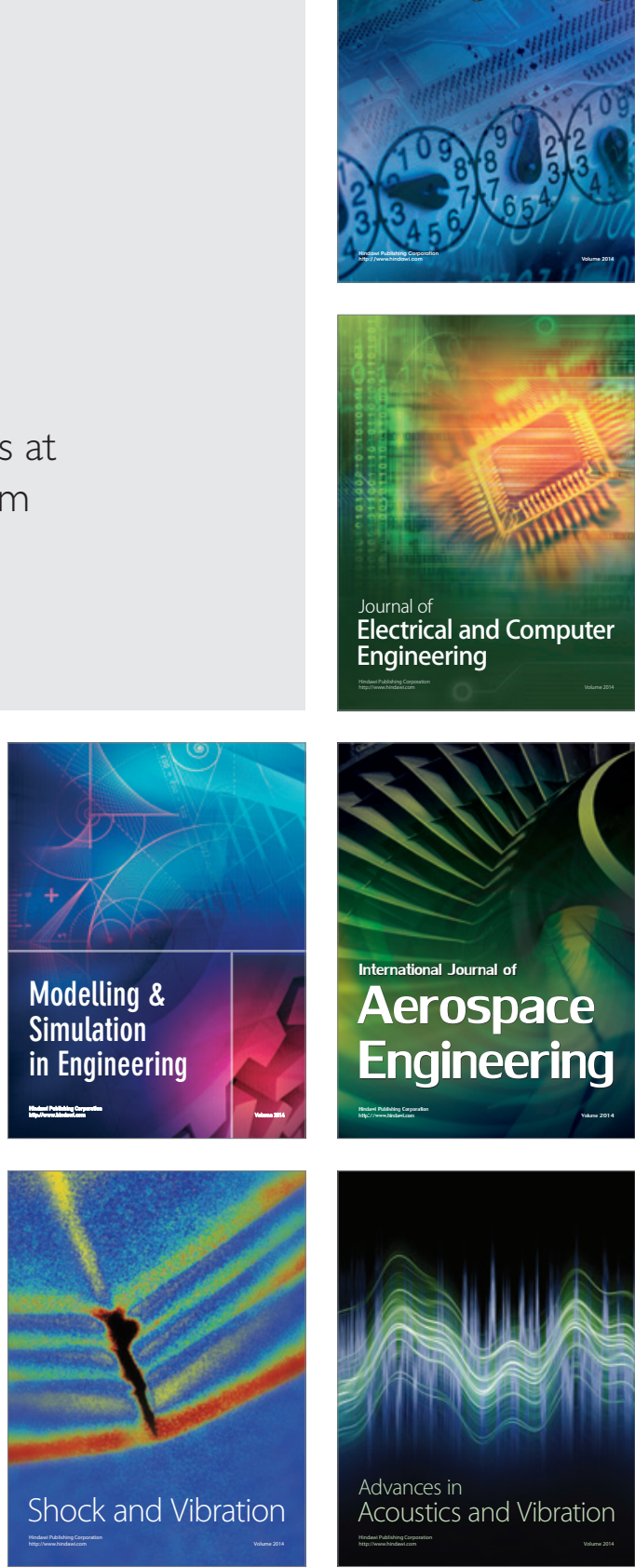